\title{
A Roundness Machine Measuring Probe Calibration
}

Jiri Vit ${ }^{1}$, Martin Novak ${ }^{2}$

${ }^{1}$ Hommel CS, Karoliny Svetle 2546, 41501 Teplice. Czech Republic. E-mail: jiri.vit@hommel-etamic.cz ${ }^{2}$ Faculty of Mechanical Engineering, J. E. Purkyne University in Usti nad Labem. Pasteurova 3334/7, 40001 Usti nad Labem. Czech Republic. E-mail: martin.novak1@fvtm.ujep.cz

The article deals with the research of the measuring probe signal of roundness machine Roundscan of Jenoptik IM producer. The probe of this machine scans geometric form as well as surface structure. The probe signal dependence on the probe arm elevation is not perfect linear and this influences the precision of evaluated form characteristics, roughness parameters as well as drall parameters. A quantification of calibration way influence on the signal characteristic was main research task. A calibration process simulator was designed and built in MATLAB for this. This article describes a way of obtaining of real probe signal. Metrological filters according current standards ISO 16610- 21 and ISO 16610-22 were built in MATLAB for obtained signal filtering. The calibrating simulator simulated various master standard values, various probe arm starting positions before the calibration, various probe arm starting positions before subsequent common measurement, and tolerance limit utilisation during a master standard value transmission to the probe signal. An efficiency of signal linearization procedure was explored, as well. Obtained results are presented as signal zones, which delimit assigned signal deviations from perfect signal characteristic.

Keywords: surface structure, probe signal, calibration, roundness machine

\section{Introduction}

A roundness machine Roundscan [1] is a device for evaluation of form deviation according ISO 1101 [2], roughness parameters according ISO 4287 [3] and thread surface structure according MBN 31007-7 [4] of rotation parts. Its inductive probe captures a deviation of a tip, which touches the part surface. A measuring amplifier then adjusts probes signal and a software evaluates it at last. Left side of Fig. 1 shows Roundscan device, right side shows the detail of its measuring probe with a tip touching a part surface.

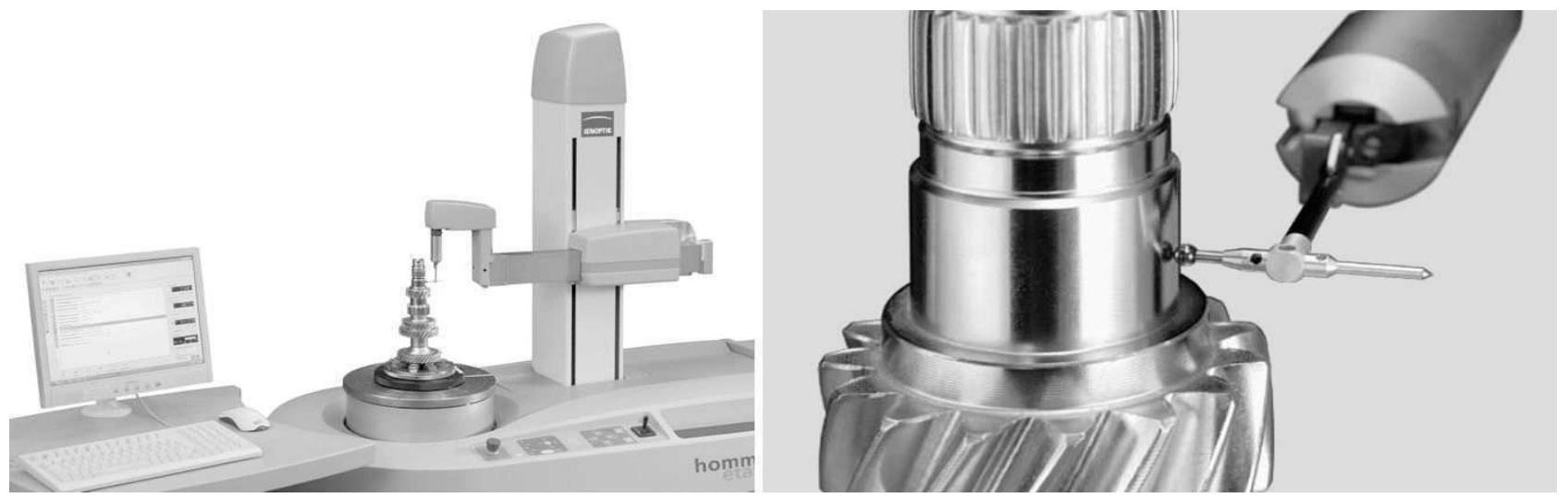

Fig. 1 Roundness machine Roundscan

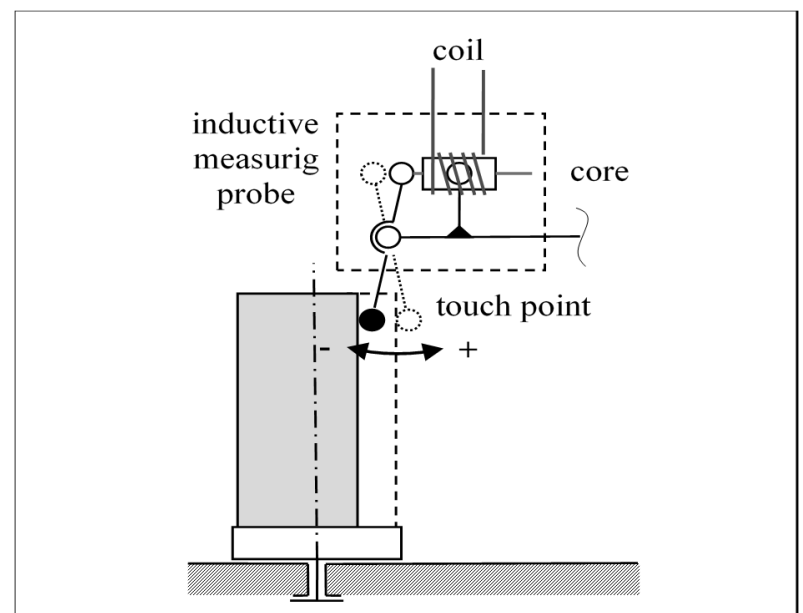

Fig. 2 Probe kinematic chart
The probe arm performs a swinging movement, according to Fig. 2. In consequence of this, the signal-arm elevation characteristic isn't linear, see Fig. 3. The object of exploration is the unknown effect of the swinging movement on the probe signal, which could to degrade the results of the roughness measurement at [5] or the circularity evaluation at [6].

Main research task is a quantification of calibration way influence on the signal characteristic was. The probe arm is pushed into the middle of its range before the profile recording, to have sufficient stroke reserve for the surface projections and depressions catching. In the middle of the range, probe signal calibration is performed as well, by which the calibration coefficient is determined by using of the circularity standard with a known circularity value. The follow-up multiplication of the probe signal by 
the calibration coefficient causes that the signal increment corresponds to the probe arm deviation in the calibrated section. The section length corresponds to the setting standard value, which is usually $10 \mu \mathrm{m}$ or $40 \mu \mathrm{m}$.

\section{Probe signal obtaining}

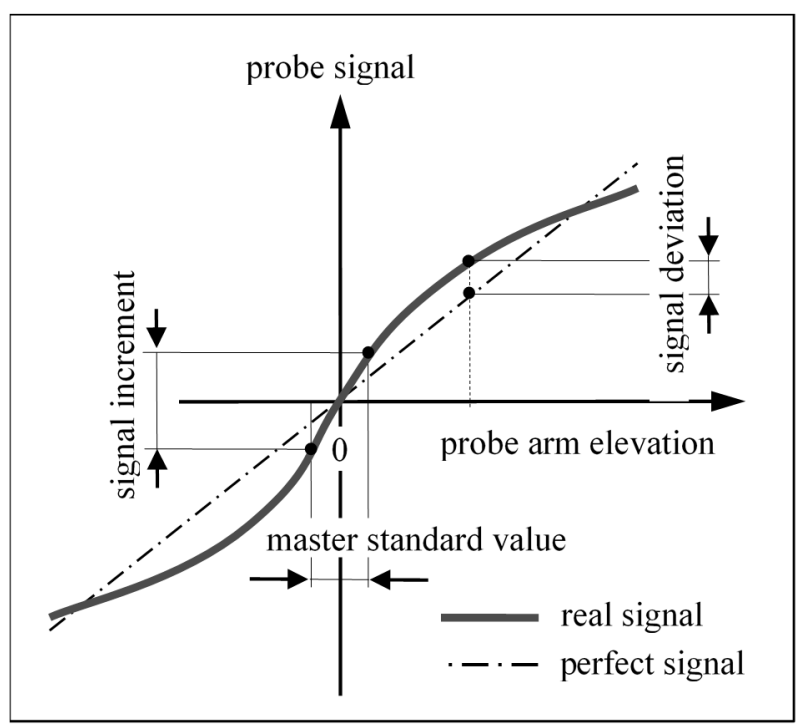

Fig. 3 Uncalibrated probe signal characteristic
The procedure for obtaining of probe real signal characteristic is next. The roundness machine horizontal arm pushes the measuring probe against a solid barrier, from the negative limit to the positive limit. Arm measuring system represents an abscissa and probe signal represents an ordinate in Fig. 3. The increment of abscissa corresponds to the arm scale resolution of $0.1 \mu \mathrm{m}$. Obtained profile is then exported from evaluating system of roundness machine and consequently processed in an calibration simulator, which was developed in Matlab [7].

\section{Probe signal calibration}

The mathematical expression of the calibration is to modify the curve of the first derivative so that the straight line joining the limit points of the calibrated section has slope equal to 1 . The simulator uses a numerical differentiation, so a filtering of signal is required at first. The simulator uses the formerly publicated procedures for profile filtering [8] and [9]. Value of 1 is forced to the curve of the first derivative in required section and then is the curve of the first derivative integrated back.

The curve of the calibrated signal is displayed in Fig. 4. The calibrated signal corresponds to the perfect signal inside the calibrated section, but its deviations grow according to the distance from the middle of the range.

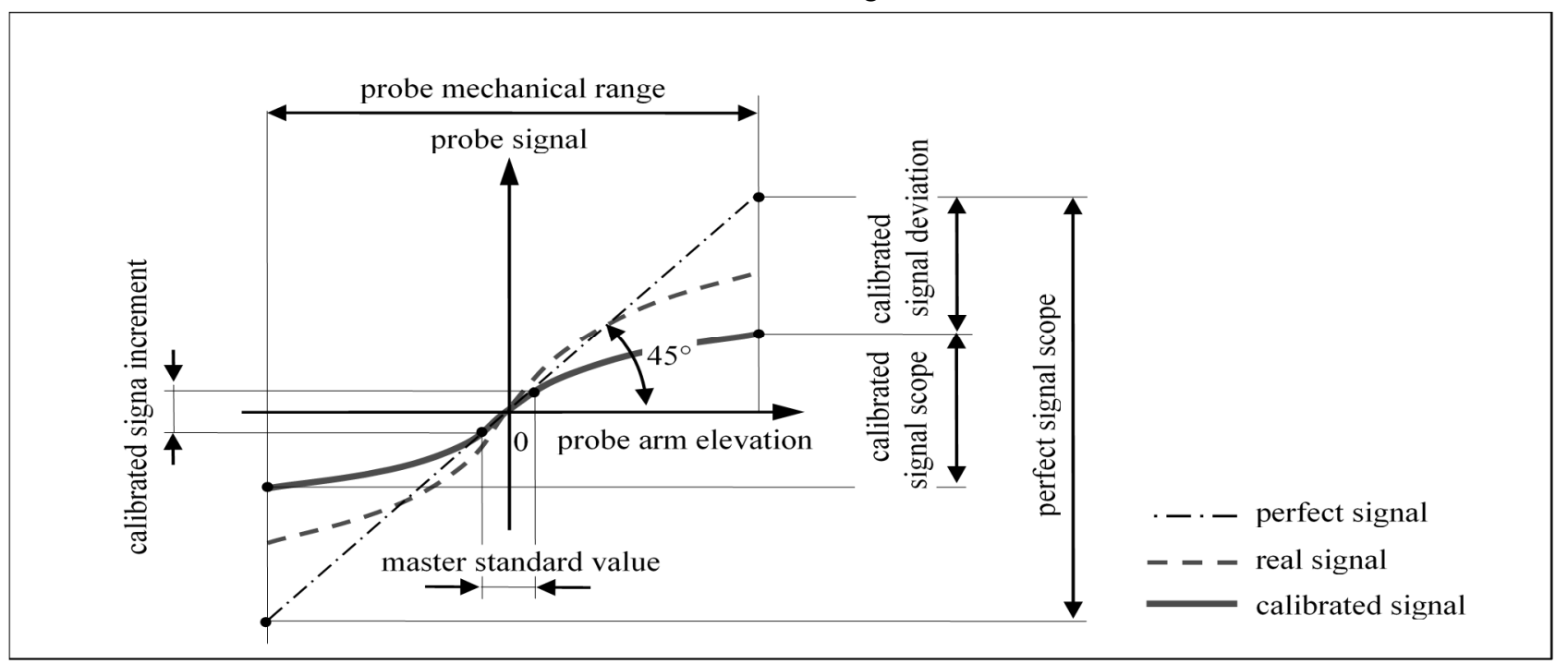

Fig. 4 Probe signal calibration chart

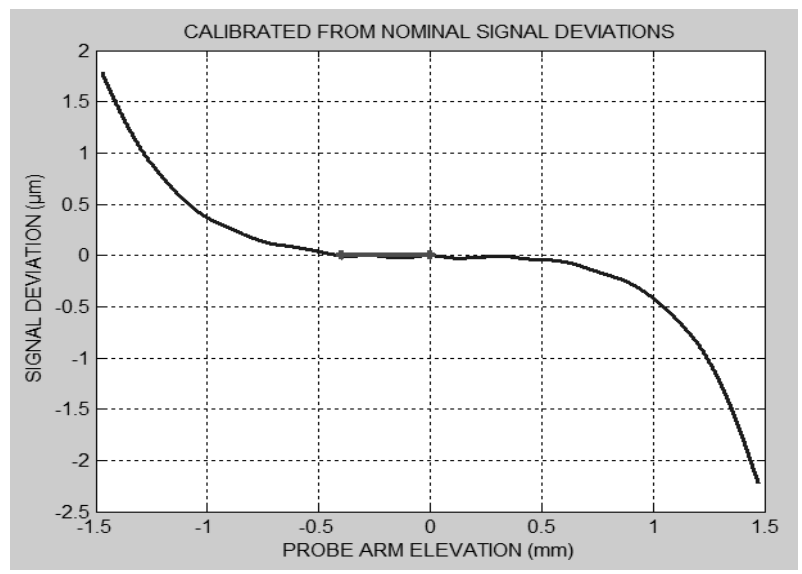

Fig. 5 Chart of deviation of calibrated signal
In the simulator executed evaluation of the signal deviations is displayed in Fig. 5. The horizontal axis corresponds to the dash-and-dot straight line of the perfect signal in Fig. 4, the origin of the coordinates represents the middle of the range and the red bold line segment marks out the calibrated signal section of $400 \mu \mathrm{m}$, in this case.

\section{Effect of master standard value}

Software simulates the calibration of the signal, which was obtained by real probe, and evaluates its deviations in zones, whose thickness is $\pm 0.1 \mu \mathrm{m}, \pm 0.2 \mu \mathrm{m}, \pm 0.3 \mu \mathrm{m}$, $\pm 0.4 \mu \mathrm{m}$ and $\pm 0.5 \mu \mathrm{m}$.

Signal deviation zones, surrounding probe arm start position of $0.0 \mathrm{~mm}$, after calibration with master standard of $10 \mu \mathrm{m}$, are displayed in left chart in Fig. 6. The limits 
of the most thickness zone $(-0.5 \mu \mathrm{m},+0.5 \mu \mathrm{m})$ are about $(-1.0 \mathrm{~mm},+1.0 \mathrm{~mm})$. The limits of the very precise signal zone $(-0.01 \mu \mathrm{m},+0.01 \mu \mathrm{m})$, are $(-62 \mu \mathrm{m},+47 \mu \mathrm{m})$.

Signal deviation zones, surrounding probe arm start position of $0.0 \mathrm{~mm}$, after calibration with master standard of $40 \mu \mathrm{m}$, are displayed in right chart in Fig. 6 . The limits of the most thickness zone $(-0.5 \mu \mathrm{m},+0.5 \mu \mathrm{m})$ are about $(-1.0 \mathrm{~mm},+1.0 \mathrm{~mm})$ again. The limits of the very precise signal zone $(-0.01 \mu \mathrm{m},+0.01 \mu \mathrm{m})$, are $(-190 \mu \mathrm{m}$,

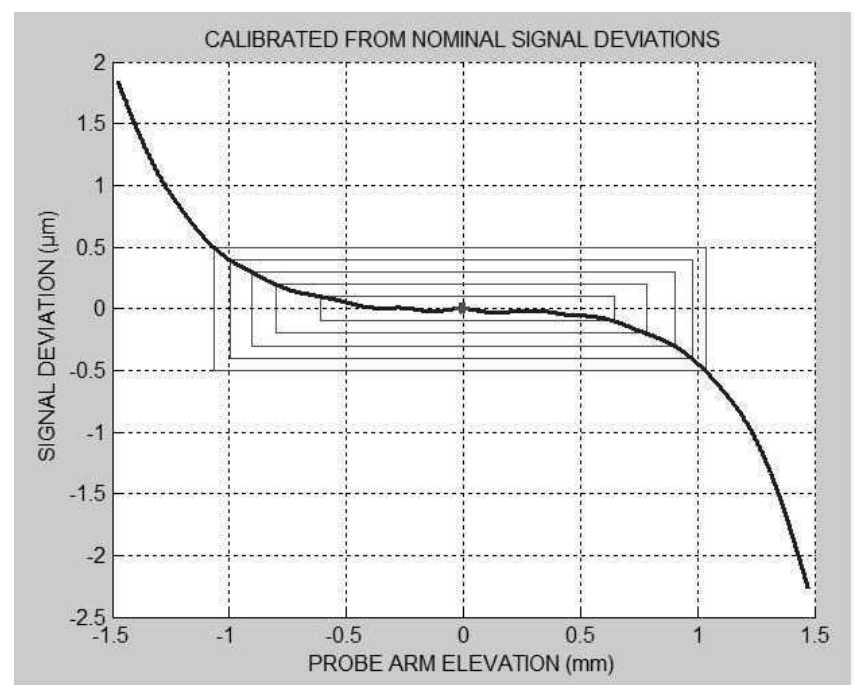

$+37 \mu \mathrm{m})$.

The differences are caused by local bumpiness in the middle of the signal curve, because the calibrated section, which is aligned with the horizontal axis, is placed just in this position. A different calibrated section length causes the different slope of the entire signal curve. By inspecting signal curves of eight probes was found out, that no accidental disturbance causes the local unevenness, but it is the systematic characteristic

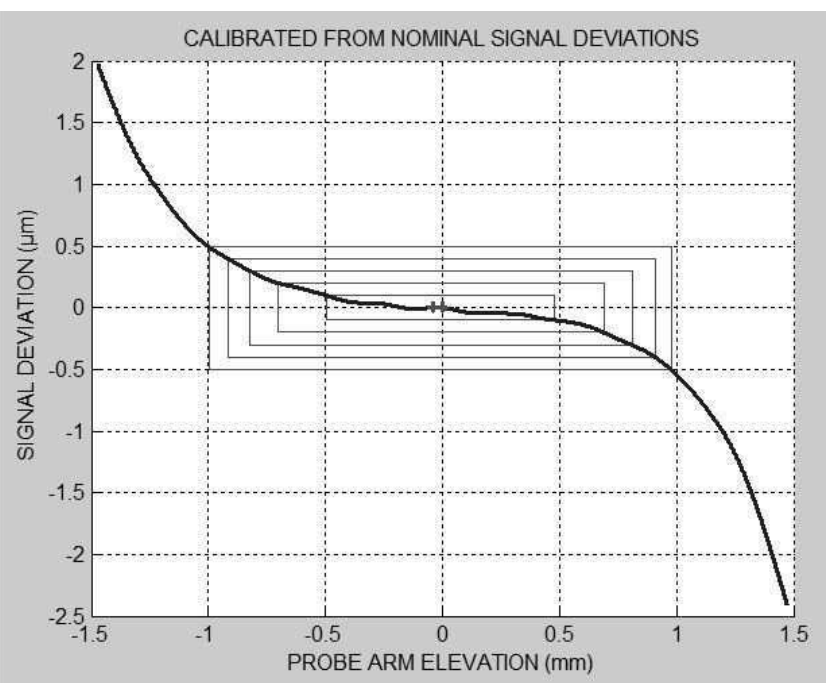

Fig. 6 Signal deviation zones for different master standard value

\section{Effect of measurement contact position}

The roundness machine measuring system enables to start recording a surface profile in different contact position from the middle of the probe range. The contact position then is not zero, but it is any position between negative and positive limit of the probe range. The reason for this is the effort to capture those projections or depressions of surface, which are supposed to exceed a half of probe range.

Signal deviation zones, surrounding probe arm start

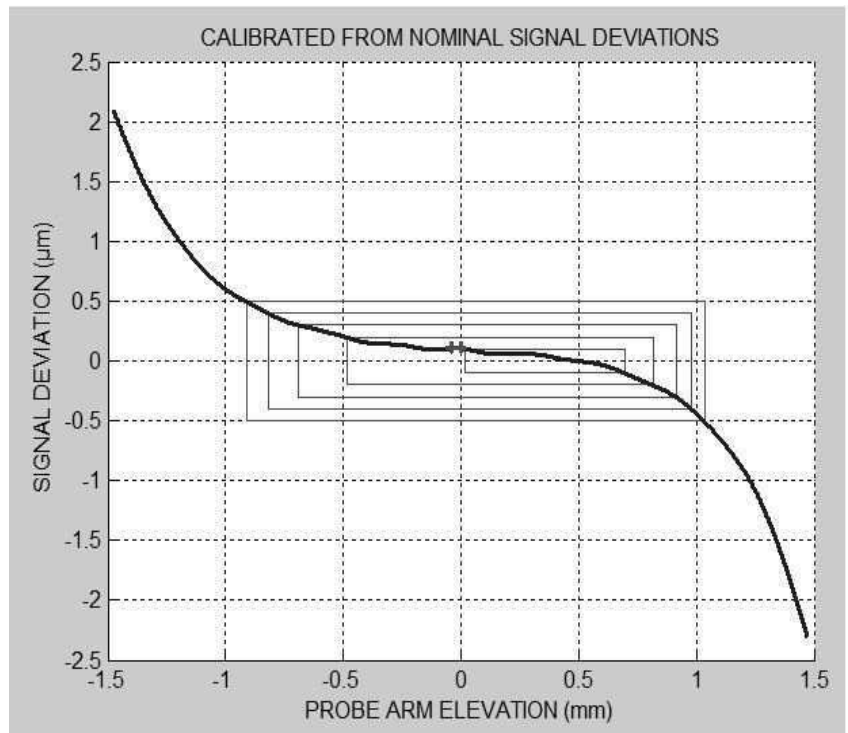

position of $+0.5 \mathrm{~mm}$, after calibration with master standard of $40 \mu \mathrm{m}$, are displayed in left chart in Fig. 7. The limits of the very precise signal zone $(-0.01 \mu \mathrm{m}$, $+0.01 \mu \mathrm{m})$, are $(-49 \mu \mathrm{m},+40 \mu \mathrm{m})$.

Signal deviation zones, surrounding probe arm start position of $+1.0 \mathrm{~mm}$, after calibration with master standard of $40 \mu \mathrm{m}$, are displayed in right chart in Fig. 7. The limits of the very precise signal zone $(-0.01 \mu \mathrm{m}$, $+0.01 \mu \mathrm{m})$, are $(-5 \mu \mathrm{m},+5 \mu \mathrm{m})$ only.

The reason is growing slope of signal curve towards to probe range limits.

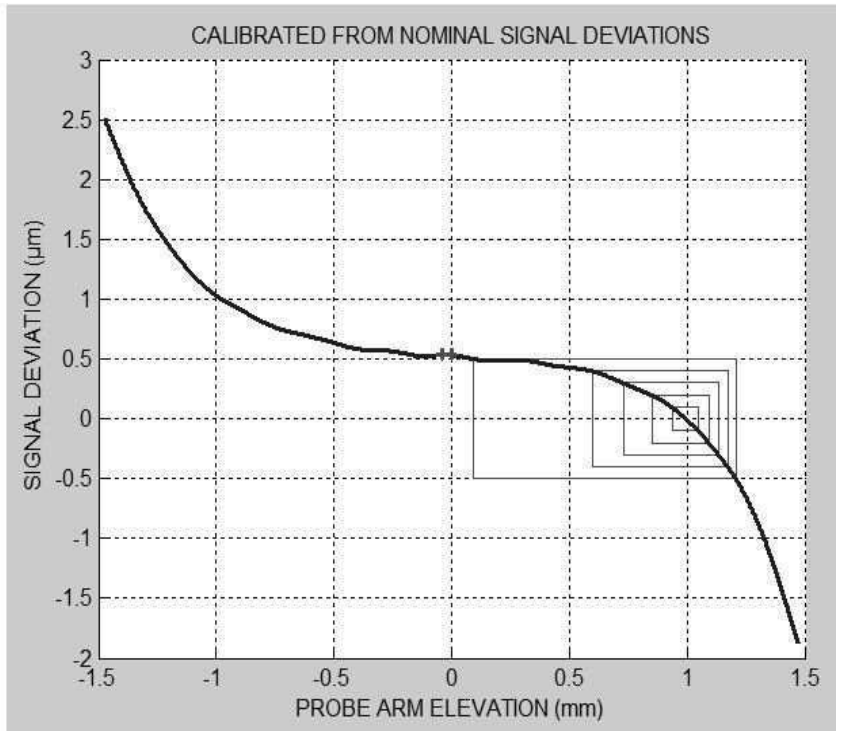

Fig. 7 Signal deviation zones for different probe arm start position 


\section{Effect of utilisation of calibration tolerance limit}

The device producer allows a tolerance limits of $\pm 0.1 \mu \mathrm{m}$ from the master standard value for calibration. This means, in fact, that the signal tangent in the calibrated section doesn't correspond to the perfect signal straight line. The tangent sloope is then different from one, see Fig. 8 and Tab. 1.

Signal deviation zones, surrounding probe arm start position of $0.0 \mathrm{~mm}$, after the calibration with utilisation of upper tolerance limit of the master standard of $10 \mu \mathrm{m}$ $(\mathrm{k}=1.01)$, are displayed in left chart in Fig. 9. The limits of the very precise signal zone $(-0.01 \mu \mathrm{m},+0.01 \mu \mathrm{m})$, are $(-1.3 \mu \mathrm{m}, 0 \mu \mathrm{m})$. The limits of the most thickness zone ($0.5 \mu \mathrm{m},+0.5 \mu \mathrm{m})$ are $(-49 \mu \mathrm{m},+50 \mu \mathrm{m})$.

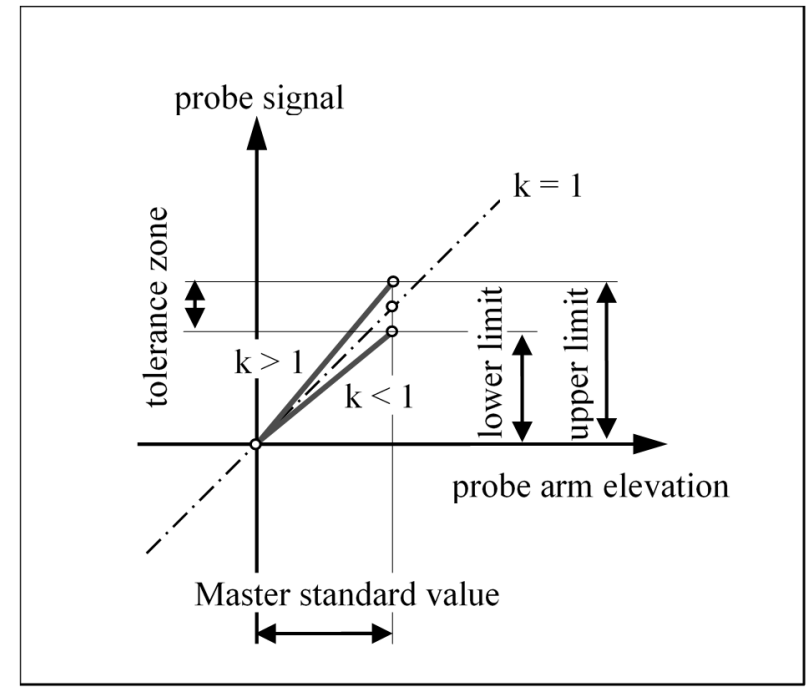

Fig. 8 Chart of probe signal slope

Tab. 1 Value of calibrated probe signal slope at master standard tolerance limit

\begin{tabular}{c||c|c||c|c}
\hline Master standard value & Lower tolerance limit & Slope $\mathrm{k}$ & Upper tolerance limit & Slope $\mathrm{k}$ \\
\hline $10 \mu \mathrm{m}$ & $9.9 \mu \mathrm{m}$ & 0.99000 & $10.1 \mu \mathrm{m}$ & 1.01000 \\
\hline $40 \mu \mathrm{m}$ & $39.9 \mu \mathrm{m}$ & 0.99750 & $40.1 \mu \mathrm{m}$ & 1.00250 \\
\hline
\end{tabular}

Signal deviation zones, surrounding probe arm start position of $0.0 \mathrm{~mm}$, after the calibration with utilisation of upper tolerance limit of the master standard of $40 \mu \mathrm{m}$ $(\mathrm{k}=1.0025)$, are displayed in right chart in Fig. 9. The limits of the very precise signal zone $(-0.01 \mu \mathrm{m}$,

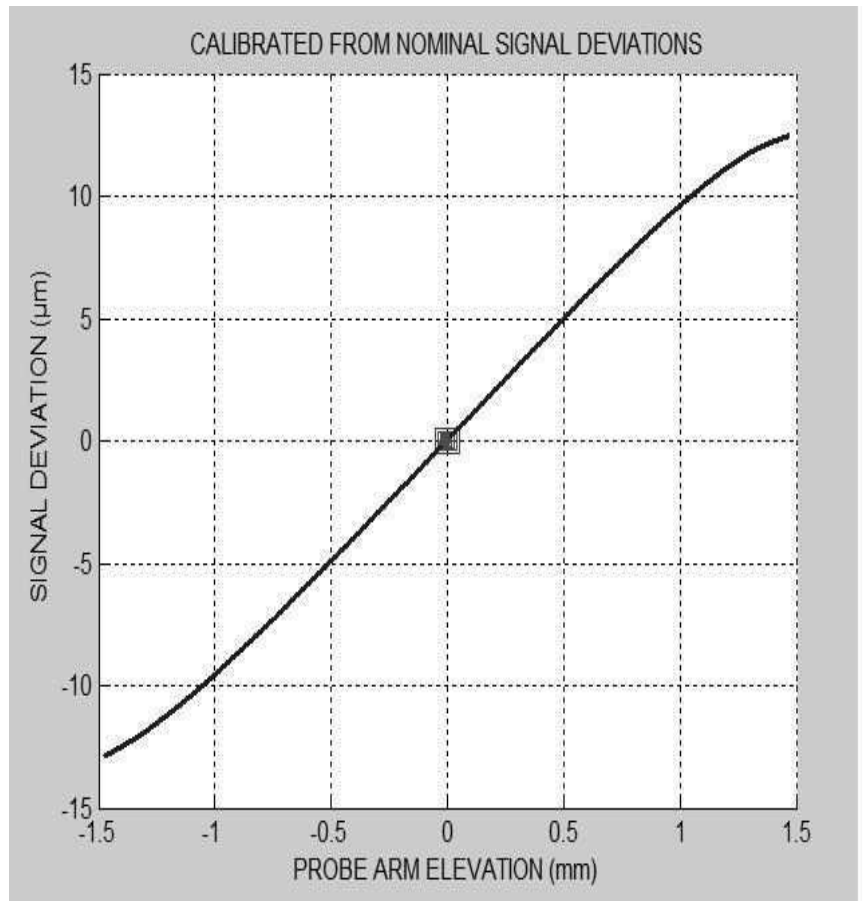

$+0.01 \mu \mathrm{m})$, are $(-4.1 \mu \mathrm{m},+3.1 \mu \mathrm{m})$. The limits of the most thickness zone $(-0.5 \mu \mathrm{m},+0.5 \mu \mathrm{m})$ are $(-206 \mu \mathrm{m}$, $+217 \mu \mathrm{m})$.

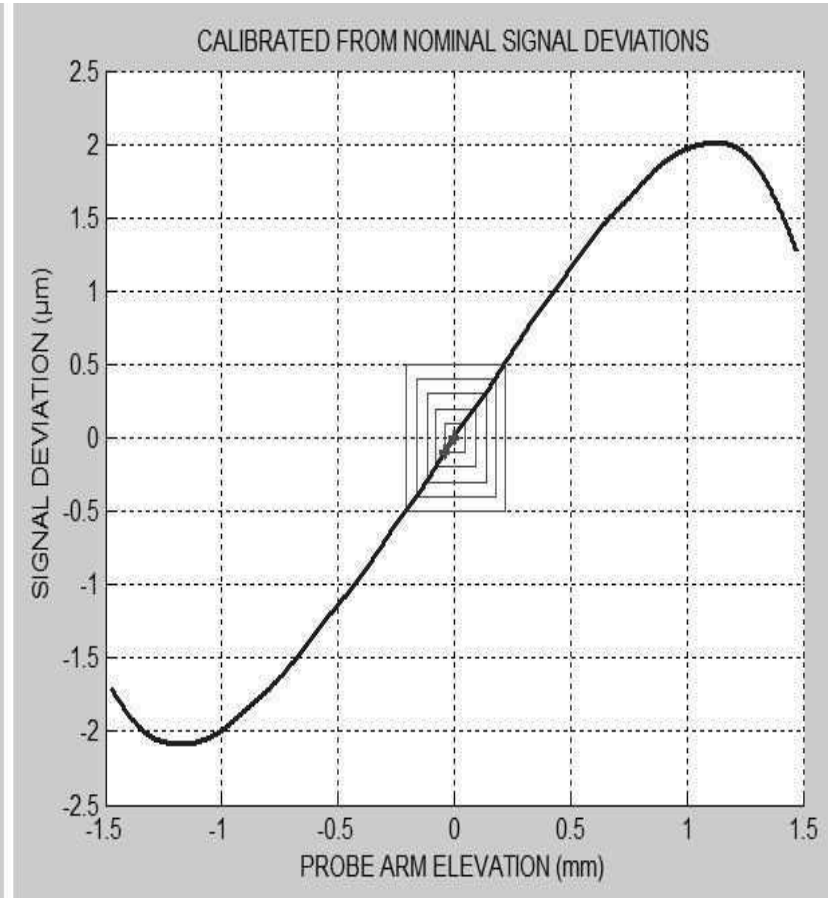

Fig. 9 Signal deviation zones after utilization of upper tolerance limit of different master standard value

By the calibration tolerance caused signal deviations are very significant. This is the reason, why the utilization of the calibration tolerances is not recommended strongly and why is necessary to effort the result, which corresponds to the master standard value precisely.

\section{Probe signal linearization}

The probe signal linearization procedure can eliminate the problem mentioned above. The signal curve obtained by this procedure is saved for follow-up compensation. 


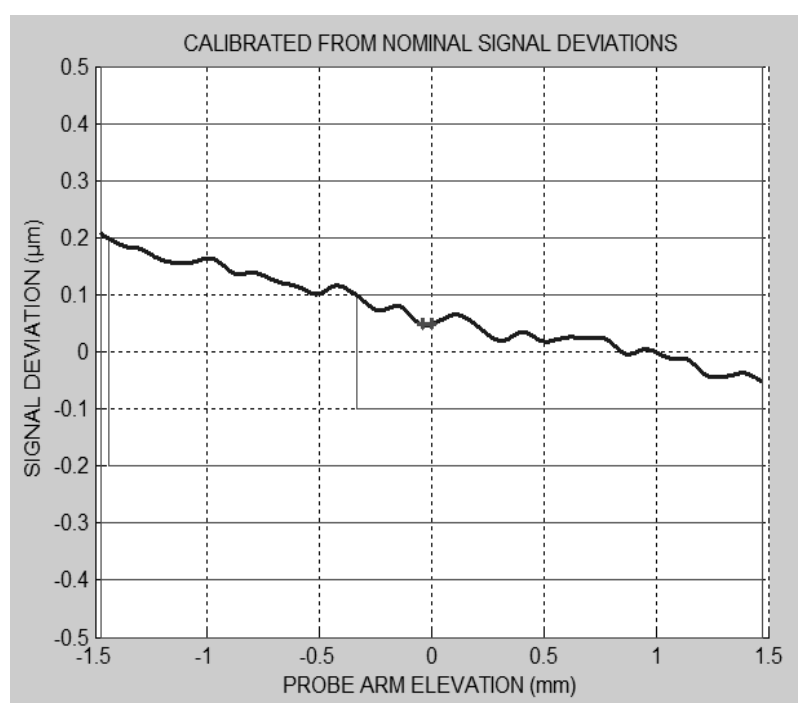

Fig. 10 Signal deviation zones, surrounding probe arm start position of $0.0 \mathrm{~mm}$, after linearization and calibration with master standard of $40 \mu \mathrm{m}$.

Probe signal from right chart in Fig. 6, after the linearization and calibration is displayed in Fig. 10. Signal deviations along the full probe range doesn't exceed the

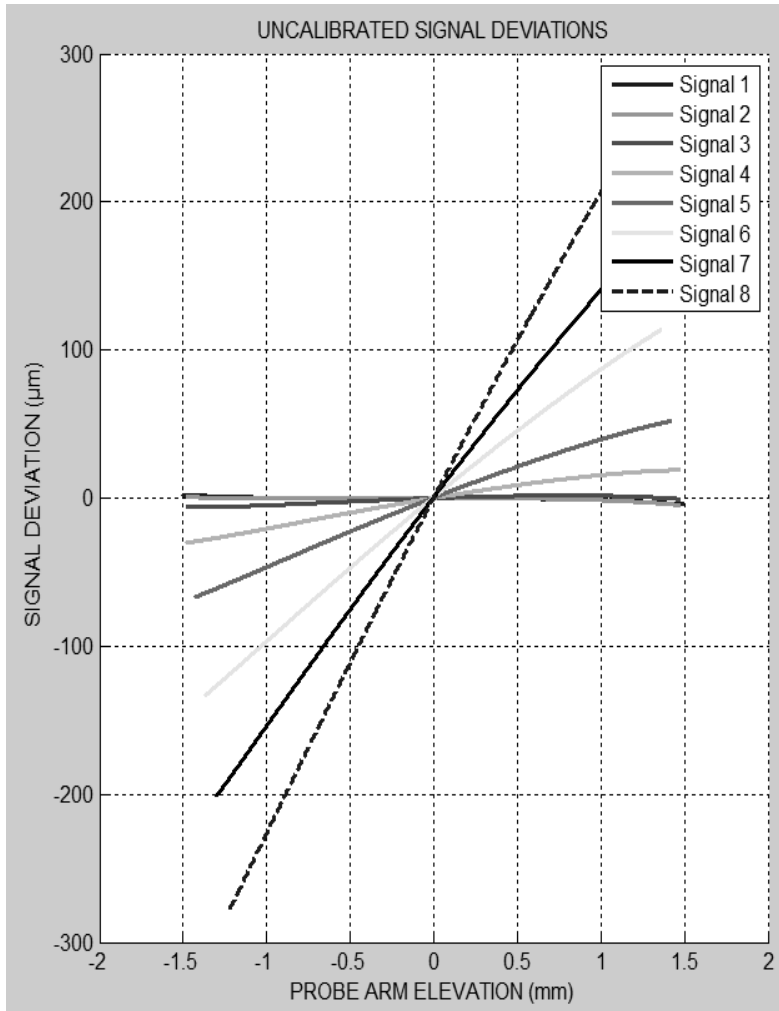

zone of the thickness of $(-0.2 \mu \mathrm{m},+0.2 \mu \mathrm{m})$. The signal straightness is much better really, but the calibrated section $(-40 \mu \mathrm{m}, 0 \mu \mathrm{m})$, which is aligned with the horizontal axis, is situated just in the local bumpiness area and this is the reason of the entire line inclination.

\section{Probe arm inclination effect}

The above-mentioned linearization, compensates not only the electrical-kinematic mechanism characteristic, but the arc effect of probe arm swinging movement as well. However, this arc effect is changing depending on the probe arm inclination, which is possible to set through the probe arm turning in the friction clutch. The signalarm elevation characteristics, without any linearization, are displayed in Fig. 11 for various probe arm inclination. Arm inclinations of individual characteristics are expressed numerically in Tab. 2.

The characteristics of the signal, which was been calibrated at the arm inclination of $-3.6^{\circ}$ only, labelled as Signal 1, are displayed in Fig. 11. The blue curve in left chart in Fig. 11 is aligned with horizontal axis just in the middle of the probe range and its first derivative (blue line in right chart) has value of 1 in this position.

Fig. 11 Probe arm inclination effect after common calibration

The characteristics of the signal, which was been calibrated at every arm inclination separately, are displayed in Fig. 12. Every curve in left chart in Fig. 12 is aligned with horizontal axis in the middle of the probe range and every first derivative in right chart has value of 1 in this position.
The linearization works well only with the same probe arm inclination, as when the linearization curve was created. Unfortunately, current roundness machine Roundscan enables to use only one linearization curve, which limits the range of the utilization of the signal linearization. 

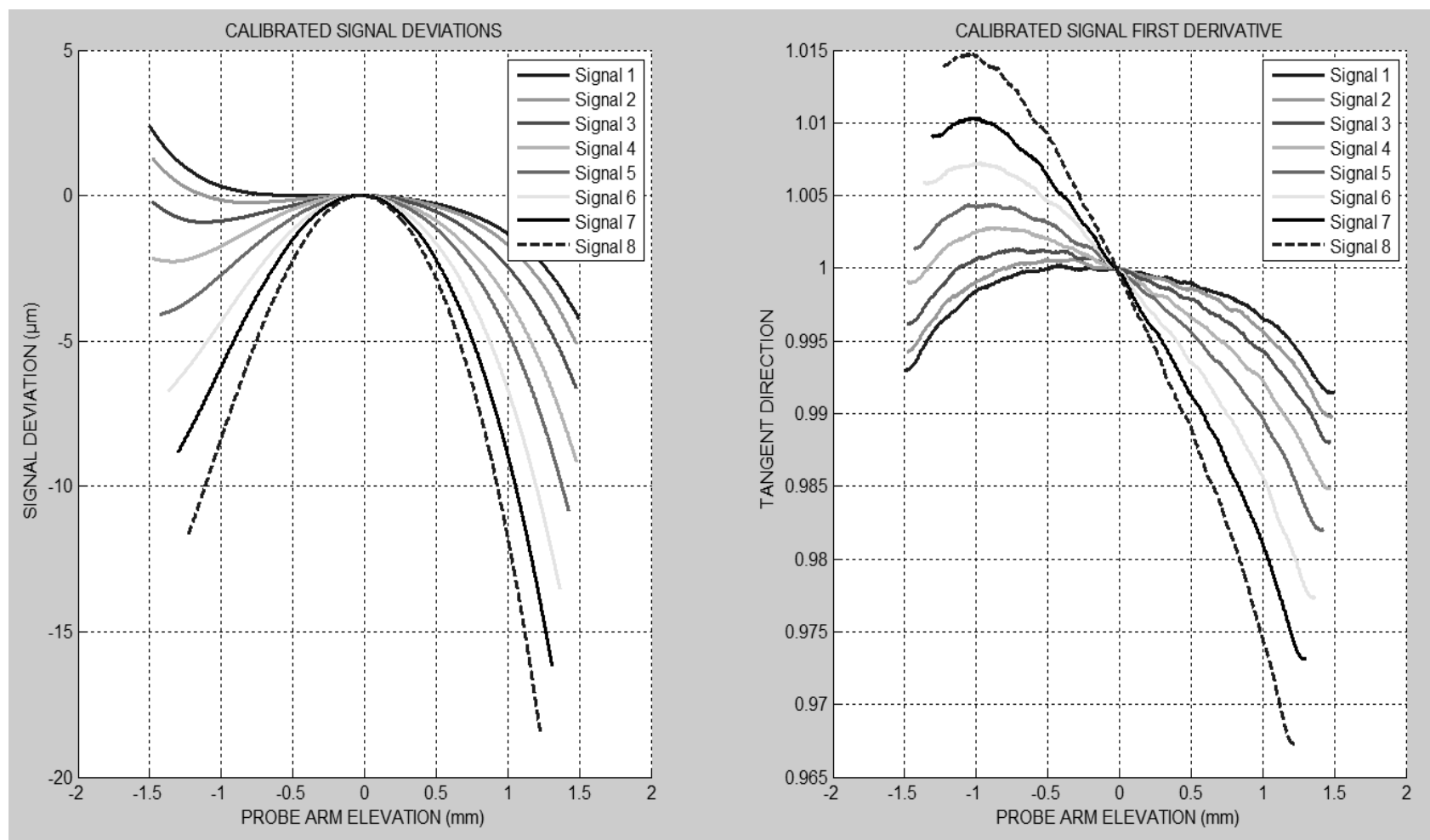

Fig. 12 Probe arm inclination effect after calibration of all position

Tab. 2 Probe arm inclination angle

\begin{tabular}{c|c} 
Characteristic indication & $\begin{array}{c}\text { Probe arm inclination } \\
\text { angle }\end{array}$ \\
\hline \hline Signal 1 & $-3.6^{\circ}$ \\
\hline Signal 2 & $0.9^{\circ}$ \\
\hline Signal 3 & $5.7^{\circ}$ \\
\hline Signal 4 & $12.1^{\circ}$ \\
\hline Signal 5 & $16.4^{\circ}$ \\
\hline Signal 6 & $23.9^{\circ}$ \\
\hline Signal 7 & $29.4^{\circ}$ \\
\hline Signal 8 & $35.8^{\circ}$ \\
\hline
\end{tabular}

\section{Conclusion}

The unprocessed probe signal shows deviations from the perfect signal, which can devaluate the measuring results, in specific cases. In case of the common form deviations, such as circularity, straightness, cylindricity or an axial flatness, is necessary to align the measured part before measuring, so that the surface deviations move the probe arm in short section of the probe range only and this section has to be located in the middle of the probe range. Requirements for form deviation of common engineering parts range from units to tens of microns. If the probe arm moves in the section of similar length, then the signal deviations are acceptable. This suggests the common parts should be aligned with residual alignment error in range of unit microns and the very precise parts should be aligned with residual alignment error up to one micron.

There is necessary to prefer the master standard with bigger circularity value, because the influence of the signal curve local bumpiness is eliminated by this way. Even the currently delivered $40 \mu \mathrm{m}$ master standard appears not sufficient. The older $400 \mu \mathrm{m}$ master standard is more suitable.

The change of the probe arm inclination to the measured part surface causes a modification of the signal characteristic, which means, that the signal first derivative of normally calibrated probe is no exactly one even in the middle of range, after arm inclination. Therefore, is very advisable to calibrate all others combinations of the arms and their slopes as well. The calibration coefficient of the measuring layout is then used together with the probe calibration coefficient, they are multiplied.

If during a very precise measurement comes to the large elevation of the probe arm, which comes for example during a form, run-out and angle of cone evaluation, during a straightness and flatness of a sloped plane evaluation, or during a polar and linear shape of piston evaluation, then is necessary to perform the probe signal linearization procedure. This linearization works well only with the same probe arm inclination, as when the linearization curve was created. Current roundness machines enable to use only one probe linearization curve, which limits the range of the utilization of the signal linearization.

\section{References}

[1] JENOPTIK INDUSTRIAL METROLOGY GERMANY GMBH. Formline: Form metrology. Document 10064360 [online pdf]. 12 2016. Web Jenoptik [2016] [Citation: 11. 11 2018.] Available on: https://www.jenoptik.com//media/websitedocuments/metrology/formline/ formline_10064360_12_2016_en.pdf 
[2] ISO 1101: 2017. Geometrical Product Specifications (GPS) -- Geometrical tolerancing -- Tolerances of form, orientation, location and run-out. Geneva: ISO, 2017-02.

[3] ISO 4287: 1997. Geometrical Product Specifications (GPS) -- Surface texture: Profile method -Terms, definitions and surface texture parameters. Geneva: ISO, 1997-04, reviewed and confirmed 2015.

[4] Draft MBN 31 007-7: 2008-09. Geometrische produktspezifikationen (GPS) -- Oberflächenbeschaffenheit -- Mess- und Auswerteverfahren zur Bewertung von drallreduzierten dynamischen Dichtflächen. Geometrical Product Specifications (GPS) - surface texture - measurement and evaluation method for the assessment of leadreduced dynamic sealing surfaces. Unknown location: Daimler [2008]. Available in Skoda Auto database of standards.

[5] MAJERÍK, J., DUBOVSKÁ, R., BAS̆KA, I., JAMBOR, J. (2018). Experimental Investigation and Measurement of Surface Roughness and Cutting Forces while Turning AlCu3MgMnPb Aluminium Alloy. In: Manufacturing Technology, Vol. 18, No. 1, pp. $66-71$.
[6] STANCEKOVA, D., MARTIKAN, P., SVOBODOVA, J., JANOTA, M., KRATOCHVIL, J. (2018). Influence of Cutting Parameters on Cylindricity Deviation by Centerless Grinding. In: Manufacturing Technology, Vol. 18, No. 4, pp. $674-678$.

[7] VÍT, J. (2017). Procedure library for roundness machine probe signal exploration. Usti nad Labem, 2017. Study for dissertation theses. Faculty of Mechanical Engineering, J. E. Purkyne University. Supervisor Martin Novak

[8] - Surface metrology open profile Gaussian filter. Library of procedures. [online]. 06. 092015. Matlab Central File Exchange. [Citation: 18. 10 2018.] Available on: http://www.mathworks.com/matlabcentral/fileexchange/52892-surface-metrology-open-profilegaussian-filter.

[9] - - Surface metrology open profile spline filter. Library of procedures. [online]. 19. 082015 Matlab Central File Exchange. [Citation: 18. 10 2018.] Available on: http://www.mathworks.com/matlabcentral/fileexchange/52562-surface-metrology-open-profile-spline-filter. 